\title{
Amor y esclavitud en la frontera sur del imperio español: la manumisión de Luis Suárez 1762-1824
}

PABLO LACOSTE*

\begin{abstract}
Resumo: Este artigo examina uma história de amor num cenário de escravidão. A manumissão de Luis Suárez e o processo judicial gerado a partir dela tem permitido conhecer detalhes interessantes sobre a dimensão emocional deste regime, que podia afetar não só a população afro-americana, mas também os criollos livres. O estudo revela sensibilidades emocionais do povo latino-americano dos extratos mais baixos do final do século XVIII.
\end{abstract}

\begin{abstract}
This article examines a story of love in a slavery scenario. A manumission of Luis Suárez and a juridical process in consequence, has allowed us to know interesting details about an emotional dimension of that regime, which could affect not only the African-American population but as well Creoles and Liberated. The research reveals emotional sensibilities of the Latin-American lower-class people at the end of the $18^{\text {th }}$ century.
\end{abstract}

Palavras-chave: Amor. Escravidão. Manumissão.

Key words: Love. Slavery. Manumission.

El amor de Pascual Suárez y Andrea Corvalán por su hijo esclavo, y su lucha por comprarle la Carta de Libertad es una de las historias más conmovedoras de la frontera austral del imperio español. Pascual era un trabajador criollo, de modesta condición social. Andrea era una mulata esclava de la hacienda de doña María Corvalán y Castilla. Se casaron en 1761 y de esta unión, un año después nació Luis, un esclavo chileno llamado a protagonizar una historia entrañable. Pascual lo amó hasta

* Universidad de Talca, Chile. E-mail: placoste@utalca.cl 
levantar un testimonio valeroso de amor paterno; se enfrentó con poderosos albaceas, revestidos de autoridad social, económica y política. El poder eclesiástico se opuso a la libertad de Luis, lo mismo que los hacendados y los jueces. Pero Pascual y Andrea siguieron luchando, y se jugaron la vida en ello. Cada paso, cada página de esta historia, está escrita con el dolor, la pasión y el amor de un matrimonio por su hijo.

El carácter dramático de esta relación estaba dado por la vigencia del régimen de esclavitud. Este fue impuesto por las grandes potencias de Europa que, entre los siglos XVI y XIX, trasladaron 12.000.000 de africanos a América. La mayor parte fueron a las grandes plantaciones de Brasil, México, el Caribe y la cuenca del Mississipi-Missouri. En otras regiones de América la esclavitud tuvo menos desarrollo cuantitativo. Por ejemplo, en el Reino de Chile, había 27.000 negros y mulatos, según el censo que mandó levantar el gobernador Agustín de Jáuregui en 1778. Aquí la esclavitud estuvo presente como sistema de vida, y dejó su huella en el dolor humano que se derramó a otras capas de la población, incluyendo los criollos del bajo pueblo.

La familia de Pascual Suárez reflejó esta mixtura entre los esclavos africanos y los criollos modestos del Reino de Chile. Y su historia, es la historia del dolor de un chileno que vivió, en carne propia, toda la rigurosidad del sistema esclavista. El casamiento de Pascual con la esclava Andrea era una modalidad relativamente frecuente en América colonial, sobre todo cuando los peones entraban en contacto con las esclavas de las haciendas. Los hijos de estas parejas quedaban dentro del régimen de la esclavitud. Pero en este caso, el padre no soportó la situación y se propuso como objetivo central de su vida, lograr la libertad de su hijo. Este plan se complicó inesperadamente, como se examina más adelante. Lo interesante es el contraste entre el amor de Pascual Suárez por su hijo, y las tensiones generadas en torno a la sociedad esclavista de la época.

\section{Andrea, mulata esclava}

Andrea Corvalán (1729-1796) era una mulata esclava chilena. Por sus venas corría sangre africana, indígena y europea. Esas mezclas formarían un volcán de energía y amor, que daría una lucha sin dar ni pedir cuartel por sus hijos. Pero antes de 
entrar en esa historia, conviene conocer algo de sus orígenes familiares. Su madre era Mariana (1694-1752), natural de Guinea. Fue trasladada de niña a América y vendida como esclava al capitán Juan Antonio Canales, militar y hacendado cuyano. En 1710 Mariana se desposó con un indio paraguayo llamado Diego; con él tuvo cuatro hijos zambos. En 1717 falleció su marido; pero cinco años después, Andrea comenzó nuevamente a procrear y tuvo siete hijos más de padre desconocido. Posiblemente el o los padres de estos niños sería un español o criollo vinculado a la propiedad de las haciendas. Uno de esos hijos fue, precisamente, Andrea. En 1743 madre (Mariana) e hija (Andrea) fueron compradas en $\$ 500$ por doña María Corvalán. ${ }^{1}$ De allí el apellido que adoptó Andrea. Laboriosa y tenaz, Andrea Corvalán logró especializarse en trabajos artesanales calificados; llegó a tener su propio torno de cernir, con el cual procesaba la harina de trigo y la separaba del salvado en el marco de la industria de los molinos harineros, entonces incipiente en Mendoza. Andrea se casó con Pascual Suárez y de esa unión nacieron tres hijos: Luis, María Dominga y Roberto. Los padres Pascual y Andrea dieron una larga batalla para obtener la libertad de Luis.

La familia Corvalán y Castilla, propietaria de la esclava Andrea, era una de las tres casas reinantes de la Provincia de Cuyo del Reino de Chile. ${ }^{2}$ El fundador fue Antonio Corvalán, hijo del chileno Juan y nieto del canario Domingo. Natural de Buenos Aires y avecindado en Mendoza, don Antonio fue capitán y encomendero. Allí desposó a Magdalena Arias Molina Videla, hija del chileno Maestre de Campo Luis Arias de Molina del Castillo. De esta unión nacieron Juan Luis, Francisco, Josefa y María, entre otros hijos. Una hija de Juan Luis, llamada María

1 "Yo don Nicolás de Allende y defensor de menores nombrado por el Cabildo... en nombre de doña Juana, doña Lorenza y doña Manuela Gil ... dichas menores tenían 2 esclavas que les había dejado doña Juana Gil, su tía, y que éstas no podían partir por ser 4 las herederas... propuse la venta a doña María Corvalán en \$ 500. - ... 1 negra llamada María, 50 años y la otra mulata llamada Andrea hija de la dicha negra en precio ambas dos en \$500. - en plata sellada... \$200. - de contado y el resto (\$300) quedan en poder de la dicha doña María a réditos pagando el interés del $5 \%$ en cada un año y declaro que dichas esclavas las hubieron dichas menores de doña Juana Gil que se las dejó por vía de limosna según consta por cláusula de su testamento y respecto de no poder ser partibles se ha determinado esta dicha venta por convenir siempre y utilidad de dichas menores. Acta dada en Mendoza, 20 de marzo de 1743". AHM, Protocolo de Escribanos n. 50, Fol. 47 v.

2 RUIZ, Jorge Comadrán. Las tres casas reinantes de Cuyo. Revista Chilena de Historia y Geografía, n. 126, Santiago de Chile (1958), p. 77-127. 
Josefa Corvalán Chirinos se casó con José Perfecto Salas, influyente hombre de gobierno en Lima y Santiago de Chile, lo cual aseguró santos en la corte para toda la familia durante largos años. ${ }^{3}$ Francisco fue alcalde de Mendoza, viticultor y transportista. El censo de 1739 le registró tropas de carretas, casas, viñas y tres esclavos, con un capital tasado en $\$ 4.000$. Por su parte, Juan Luis Corvalán y Castilla fue una figura prominente en Mendoza colonial. En el censo de 1739, Juan Luis Corvalán figuraba como propietario de una tienda, chacras con viña, casas y seis esclavos, totalizando bienes por \$12.000. Juan Luis se casó con Angela Chirinos de Posadas, nieta del Maestre de Campo don Francisco Chirinos de Posadas, quien fue gobernador del Fuerte de Valdivia y dos veces corregidor de Cuyo (1671-1672 y 1676-1677); hijos de Juan Luis y Angela fueron Francisco de Borja y la mencionada María Josefa. El primero fue padre de María Josefa Corvalán Rosas, casada con José Agustín Sotomayor, abogado de las reales audiencias de Santiago de Chile y Buenos Aires. Es importante retener este personaje por el papel que le cupo más tarde en el pleito de la libertad del esclavo Luis Suárez. Su hermana María Corvalán y Castilla también se casó con un personaje de alcurnia: su marido fue el capitán Luis Chirinos de Posadas, hombre de acción y emprendedor, propietario de uno de los más importantes molinos de Mendoza, tasado en \$1.000, y tres esclavos. ${ }^{4} \mathrm{La}$ disponibilidad de capital, la influencia económica en el transporte y la agroindustria, y la calidad de los lazos sociales encumbraban a la familia Corvalán y Castilla en el centro del poder de Cuyo.

3 Danoso, Ricardo. El Dr. José Perfecto de Salas, fiscal de la Audiencia de Chile. Revista de Historia Americana y Argentina n. 3 y 4, Mendoza, 1958-1959, p. 33-54.

4 Censo de propiedades de 1739. Reproducido en Coria, p. 300. 


\begin{tabular}{|c|c|c|}
\hline Corvalán & $\begin{array}{l}\text { Intonio } \\
\text { Castilla }\end{array}$ & $\begin{array}{l}\text { Magdalena } \\
\text { Arias de Molina }\end{array}$ \\
\hline$\downarrow$ & $\downarrow$ & $\downarrow$ \\
\hline Juan Luis & Francisco & María (ama de Luis Suarez) \\
\hline Corvalán y Castilla & Corvalán y Castilla & Corvalán y Castilla \\
\hline cc Angela Chirinos & cc Clara Escalante & $\overline{\text { cc Luis Chirinos y }}$ \\
\hline de Posadas 21/6/1721 & $22 / 4 / 1733$ & Posadas 26/8/1738 \\
\hline $\begin{array}{l}\text { Libro Mat.1702-1742, f.91. } \\
\qquad \downarrow\end{array}$ & $\begin{array}{c}\text { Libro Mat.1702-1741, f.175. } \\
\qquad \downarrow\end{array}$ & $\begin{array}{c}\text { Libro Mat-1702-1742, f.245. } \\
\qquad \downarrow\end{array}$ \\
\hline & $\begin{array}{c}\text { Hija natural con María Videla: } \\
\qquad \downarrow\end{array}$ & Sin sucesores. \\
\hline Francisco Borja & Petrona (ama de L & uis Suarez) \\
\hline Corvalán & Corvalán & \\
\hline cc María del Carmen & cc Juan Martín Puebla & \\
\hline Martínez de Rosas & $16 / 2 / 1749 \rightarrow$ & \\
\hline $26 / 6 / 1769 \rightarrow$ & Inf. Mat, año 1749, en & uadernadas, f.7. \\
\hline $\begin{array}{c}\text { Inf.Mat, año 1769, caja №6. } \\
\downarrow\end{array}$ & $\downarrow$ & \\
\hline María Josefa $\leftarrow$ Primos & In $2^{\circ}$ grado $\rightarrow$ Estanislao $(\mathrm{am}$ & de Luis Suarez) \\
\hline $\begin{array}{l}\text { Corvalán } \downarrow \\
\text { CC José Agustín Sotoma }\end{array}$ & $\begin{array}{l}\text { Puebla } \\
\text { Ior cc Bernabela C }\end{array}$ & Irreras \\
\hline $15 / 12 / 1788$ & 9/2/1778 & \\
\hline Libro Mat.1775-1800, f.183v. & Libro Mat.1775/18 & 00 , folio $24 \mathrm{v}$. \\
\hline
\end{tabular}

Abreviaturas: Libro.Mat = Libro Matrimonios; Inf.Mat.= Informaciones Matrimoniales; $\mathrm{cc}=$ casado $/ \mathrm{a}$ con; $\rightarrow=$ en adelante $; \mathrm{f}=$ folio; $\mathrm{v}=$ vuelta.

Fuente: cuadro elaborado por el investigador genealógico Luis César Caballero, a partir de los libros de la Parroquia Matriz de Mendoza, Archivo del Arzobispado de Mendoza.

Doña María Corvalán y Castilla asumió el control de las propiedades familiares por su temprana viudez. En 1739 su marido enfermó gravemente; incapaz de realizar su testamento, debió contentarse con elaborar un poder para testar a nombre de su esposa y otro pariente. ${ }^{5}$ Poco después, don Luis Chirinos de Posadas falleció y su viuda asumió la dirección de su hacienda que incluía el molino harinero y los esclavos. ${ }^{6}$ La mujer también

5 Testamento del capitán Antonio Corvalán, Mendoza, 5 de agosto de 1739. AHM, Protocolo de Escribanos n. 46, fols. 112-115. Poder para testar otorgado por el capitán Luis Chirino de Posada, Mendoza, 16 de junio de 1739. AHM, Protocolo de Escribanos n. 46, fols. 86-87.

6 Don Luis de Chirinos dispuso un censo de $\$ 400$ sobre este molino harinero; este fue redimido en noviembre de 1768. Protocolo de Escribano 88, Mendoza, 10 de noviembre de 1768 , fols 70 v. -72 . 
se convirtió en propietaria de unas valiosas tierras ubicadas junto al Camino Real, media legua al norte de la plaza de Mendoza. ${ }^{7}$ Doña María no volvió a casarse y durante cuarenta años mantuvo su plena autonomía legal y económica. Paralelamente fortaleció los lazos con su familia, especialmente con sus hermanos y sobrinos.

Dentro del ethos sociocultural de la familia Corvalán y Castilla, la posesión de esclavos era una característica importante. Como se ha señalado, el censo de 1739 reflejó la fuerte tendencia esclavista del grupo. Las casas de los tres hermanos tenían esclavos: Juan Luis poseía seis, Francisco tres y María otros tantos. Al parecer, esta tradición la inició don Francisco Corvalán. En el contexto de sus viajes con las tropas de carretas, en 1731, don Francisco "compró dos negras en Buenos Aires, una de las cuales, llamada Petrona, se la prestó a su hermana, Josefa Corvalán". A partir de entonces comenzó la reproducción de la fuerza de trabajo esclava, pues "esta Petrona es madre de tres hijos, Ana, María e Hilario; la primera madre a su vez de Miguel y la segunda de José, Maria, Clara y Prudencia”. En una declaración posterior, don Francisco Corvalán afirmó que "por haber salido Hilario muy malo, lo vendió, quedándose todos los demás en casa de doña Josefa Corvalán que los quería por haber vivido Petrona con ella treinta y seis años, motivo por el cual no se los quitó". 8 Tras el fallecimiento de doña Josefa se produjo un conflicto de intereses en torno a los derechos de propiedad sobre estos esclavos. Por un lado, don Andrés Antonio Moyano, sobrino de Josefa, se consideró dueño de aquellos por haber sido nombrado albacea y heredero. 9 Por otro, don Francisco Corvalán se consideraba propietario de los esclavos por haberle prestado a su hermana la primera mujer que engendró a todo el grupo de esclavos. Mientras doña Josefa vivía, se mantuvo el statu quo; pero inmediatamente después de su muerte (5 de marzo de 1767), su hermano se apoderó de los esclavos a viva fuerza. Don Andrés Moyano describió el episodio en los siguientes términos:

7 Imposición de censo de tierras de don Onofre Lemos, Mendoza, 20 de octubre de 1779, Protocolo de Escribanos n. 104, 20 de octubre de 1779, fols. 83 v. Escribano José Lagos, p. 72.

8 Espejo, Juan Luis. La provincia de Cuyo del Reino de Chile. Santiago: Fondo Histórico y Bibliográfico José Toribio Medina, 1954, tomo II, p. 691.

9 Testamento de Josefa Corvalán, Mendoza, 25 de febrero de 1763. AHM, Protocolo de Escribanos n. 70 fols. 24 v.-26. 
como a las siete de la noche, mientras se velaba el cuerpo de su tía, doña Josefa Corvalán en la Iglesia de Santo Domingo, y aprovechando que la casa estaba sola, don Nicolás y don Francisco Corvalán, hijos del maestre de campo don Francisco Corvalán, con gente armada, le sustrajeron de ella siete esclavos de la dicha doña Josefa. 10

Este episodio, además de reflejar la codicia de los Corvalán por la posesión de los esclavos, generó un juicio por restitución de esclavos. En las actuaciones se tomó declaración a doña María Corvalán, hermana de doña Josefa y de Francisco, la cual aportó información sobre el origen de los fondos que utilizó este último para adquirir los primeros esclavos en Buenos Aires. Tras evaluar las pruebas, la Real Audiencia de Chile produjo una sentencia por la cual atribuyó los esclavos a Francisco Corvalán (14 de marzo de 1772).

En este contexto, doña María redactó dos testamentos con referencias al esclavo Luis, uno en 1765 y otro en $1776 .{ }^{11}$ En ambos designó como heredera a una sobrina, doña Petrona Corvalán, hija natural de uno de sus hermanos. ${ }^{12}$ Petrona se entroncó con una peculiar familia chilena al casarse en 1749 con Juan Martín de Puebla, nieto del capitán Juan de Puebla y Reinoso. Tal como se verá más adelante, los antecedentes singulares de los Puebla se iban a hacer sentir en esta historia de esclavos. Pero dejemos por ahora ese asunto y digamos que doña Petrona heredó el molino, una huerta de árboles y varios esclavos. ${ }^{13}$ Pero además, doña María Corvalán cedió algunos bienes a los hijos de su sobrina Petrona, María Josefa Puebla y Estanislao Puebla. A este último se le concedió la propiedad del mulatillo Luis Suárez. Como albacea testamentario se nombró al padre Martín Ladrón de Guevara, otro actor clave de esta trama.

10 Espejo, Juan Luis. La provincia de Cuyo del Reino de Chile. Santiago: Fondo Histórico y Bibliográfico José Toribio Medina, 1954, tomo II, p. 690.

11 Testamento de María Corvalán de Castilla, Mendoza, 9 de octubre de 1765. AHM, Protocolo de Escribanos n. 81 fols 89-94.Testamento de María Corvalán y Castilla, Mendoza, 12 de diciembre de 1776. AHM, Protocolo de Escribanos n. 100 fols 153 v.155.

12 Doña Petrona era hija natural de Francisco Corvalán. Poder para testar otorgado por Petrona Corvalán, Mendoza, 23 de junio de 1781. AHM, Protocolo de Escribanos n. 106 fols 193-194; Testamento de Petrona Corvalán, Mendoza, 27 de julio de 1793. AHM, Protocolo de Escribanos n. 124 fols. 72.

13 Testamento de doña Petrona Corvalán, Mendoza, 27 de julio de 1793. Protocolo de Escribanos n. 124, fols. 72. Escribano José Lagos, p. 169. 


\section{El padre Martín, especialista en testamentos}

El padre Martín Marcos Ladrón de Guevara pertenecía a otra familia troncal de Cuyo. Entre sus parientes había corregidores, terratenientes, viticultores y clérigos. Entre ellos figuraban su tío homónimo y su hermano, el padre Domingo Ladrón de Guevara y Zapata. El padre Martín nació y murió en Mendoza (1745-1815). Hábil en el plano de las letras, fue maestro de filosofía. Pero su fuerte fue la trayectoria eclesiástica: ordenado sacerdote muy joven (1769), cumplió una carrera destacada en el clero, pues le tocó subrogar al padre Francisco Correa de Saá, la mayor autoridad eclesiástica de Mendoza durante tres décadas. Fue coadjutor y vicario interino de la Iglesia Matriz de Mendoza. ${ }^{14}$ Junto al padre Francisco, el joven padre Martín aprendió el oficio de conducir la Iglesia en Mendoza, como los aprendices se empapaban de las enseñanzas de los maestros. Las prácticas, los usos y costumbres se transmitían de esa manera, con la vida misma. El padre Martín aprendió del padre Francisco, a través de su ejemplo, que era perfectamente compatible la vida dedicada a Dios, y la participación en el tráfico negrero. En efecto, el padre Francisco compraba y vendía esclavos. Los adquiría en el puerto de Buenos Aires y los vendía en el Reino de Chile. Así por ejemplo, en 1730, el padre Francisco compró a la South Sea Company ocho negros destinados al mercado de Cuyo y Chile. ${ }^{15}$ Junto con estas enseñanzas, el padre Francisco transmitió también otras enseñanzas de tipo religioso, como por ejemplo, las instrucciones que había recibido del obispo de Santiago de Chile Juan González Melgarejo. Entre otras indicaciones, el prelado le indicaba que

visitéis todas las iglesias, hospitales, ermitas, capillas, altares, oratorios y demás lugares píos a Nos sujetos y que por derecho o costumbre, deben ser o por Nos o por nuestros visitadores visitados y los sagrarios y lugares donde está el Santísimo Sacramento, pilas de bautismo, crismeras y reliquias, ornamentos, aras corporales, cálices y custodias; tomando en cuenta a los mayordomos de las fábricas y colectores de Misas y cobrar los alcances; y visitar todas las memorias, aniversarios, capellanías, cofradías y obras pías, testamento y todas las demás cosas que debáis visitar y requieran visitación y hacer cumplir lo que estuviere y nombrar mayordomos y colectores, asimismo podáis inquirir y castigar los pecados públicos. 16

14 Verdaguer, Aníbal. Historia Eclesiástica de Cuyo. Milán: Premiata Imprenta Salesiana, 1932, p. 1, 433.

15 Studer, Elena de. La trata de negros en el Río de la Plata en el siglo XVIII. Buenos Aires: Universidad de Buenos Aires, 1958 (citada en Fageström, René Peri. La raza negra en Chile, una presencia negada. Santiago: Lom, 1999, p. 166).

16 Verdaguer, Historia Eclesiástica..., p. 1, 333-334. 
Esas instrucciones eran como el plan de trabajo que el padre Francisco aprendió a cumplir a lo largo de su gestión al frente de la iglesia mendocina. Y dentro de estas actividades, una de las que cumplió con mayor celo fue, precisamente, la intervención en los testamentos. Posteriormente, esta tradición fue continuada por el padre Martín. Con frecuencia, el clérigo lograba que las personas mayores, en edad de redactar sus testamentos, cayeran dentro de su esfera. El los acompañaba en el trance de la cercanía de la muerte, y los orientaba en la forma de lograr un mejor aprovechamiento de sus bienes, tanto para el tramo final de su vida, como para la salud de su alma después de la muerte, en las angustiosas horas del purgatorio. El padre Martín participó en la redacción de diecisiete testamentos, codicilios o poderes para testar. En algunos casos fue testigo, en otros beneficiario y en nueve oportunidades fue nombrado albacea testamentario. ${ }^{17}$ En este sentido, el juicio por la libertad del mulatillo Suárez tuvo un significado clave para la carrera del padre Martín: en ese pleito, el sacerdote demostraría su capacidad para defender el patrimonio de las familias dominantes de Mendoza. El conflicto sería un paso clave para su carrera pues sería una clara oportunidad de exhibir su confiabilidad como albacea y administrador de bienes.

\section{Pascual Suárez, un padre de familia en el bajo pueblo chileno}

Contrastando con la elevada posición social de la familia Corvalán y Castilla, el perfil socioeconómico de Pascual Suárez se asimila a los sectores criollos del bajo pueblo. Los Suárez no eran una familia de la élite local, motivo por el cual no se conocen árboles genealógicos de sus miembros. Se sabe que algunos de ellos

17 Entre las personas que nombraron al padre Martín como albacea testamentario podemos citar a Josefa Guevara (12 de agosto de 1776), María Corvalán (12 de diciembre de 1776), Nicolás Álvarez (22 de junio de 1801), María Josefa Puebla (29 de junio de 1786), Josefa Gómez (3 de junio de 1788), Petrona Corvalán (27 de julio de 1793), Domingo Guevara (25 de octubre de 1802), Juan Nepomuceno Chenaut (13 de enero de 1806), Antonio Zapata (12 de diciembre de 1807). También participó en el codicilio de Manuel Coria (10 de marzo de 1800) y en el testamento de Pedro Pablo Gómez (6 de noviembre de 1801). Fue testigo de los testamentos de Agustín Videla (15 de noviembre de 1800), Manuela Pena (25 de agosto de 1806), Antonio Casal (20 de agosto de 1806), Manuel Silva (29 de diciembre de 1810) y del poder para testar de José León Videla (23 de agosto de 1807. Nicolás Alvarez de Miranda dio en su nombre, el poder para testar (22 de junio de 1801) (Codoni, Elvira Martín de; y Gabbi, Alicia Virginia. Mendoza en sus testamentos siglos XVIII y XIX 1751-1810. Mendoza: Facultad de Filosofía y Letras, 1998, p. 260-342). 
eran portugueses y, a mediados del siglo XVIII, se ganaban la vida en Mendoza como artesanos calificados; entre éstos se encontraba el zapatero Francisco Suárez y el herrero Juan Suárez. ${ }^{18}$ El primero de los nombrados tuvo un altercado con el capitán de Comercio, José Amoroso, motivo por el cual un grupo de vecinos notables de Mendoza solicitó la expulsión de los portugueses radicados allí.19 Siempre dentro del espacio de sectores populares, otros miembros de la familia Suárez estaban cerca del mundo de la esclavitud. Así, por ejemplo, Félix Suárez era un mulato esclavo que logró comprar su propia libertad en $\$ 280$ en 1778.20

La vida de Pascual Suárez fue la de un "guacho" de los sectores populares criollos. Nació en Santiago del Estero, hijo natural de Juana Suárez y de padre desconocido. Posteriormente se radicó en Mendoza, donde cultivó su vida social de amores y amistades. Aunque era analfabeto, se ganó la confianza de José Gabriel Chacón, el cual sería su "testigo a ruego" en los pleitos judiciales.

A pesar de su oscuro origen, Pascual Suárez logró un modesto progreso debido a su laboriosidad en las tareas agrícolas. Con sus ahorros logró convertirse en propietario de dos pequeños terrenos. En 1778 adquirió por $\$ 12$ "un pedazo de tierra a extramuros de esta ciudad, para el norte, media legua poco más o menos de la plaza. Se compone de $8 \frac{1}{2}$ varas de frente por el naciente y poniente y 150 varas de fondo". ${ }^{21} \mathrm{El}$ terreno se hallaba muy próximo a las tierras de doña María Corvalán, que se encontraban también media legua al norte de la Plaza. Pascual compró este sitio para levantar allí una modesta casa y vivir junto a su esposa y sus tres hijos esclavos. Poco después, en 1779, Suárez adquirió por \$12 "un retazo de tierras, a extramuros de esta ciudad para el norte. Se compone de $18 \%$ varas de ancho y 75 varas de largo". 22 Una década más tarde, las propiedades de Suárez fueron descriptas en los siguientes términos: "media cuadra de tierra, a extramuros de la ciudad, en paraje peligroso, en donde mantengo un rancho, sin árboles de ninguna calidad y en el mayor desamparo". "23 La ausencia de árboles no era por pereza de su morador, sino "por tratarse

18 Matricula de extranjeros, Mendoza, 13 de mayo de 1754. Espejo, tomo II, p. 657.

19 Espejo, tomo 2, p. 647.

20 Manumisión de Félix Suárez, Mendoza, 29 de abril de 1778. AHM, Protocolo de Escribanos n. 104, fols. 57.

21 Escritura de compra-venta, Mendoza, 29 de octubre de 1778. Protocolo de Escribanos n. 104 , fols. 149.

22 Escritura de compra-venta, Mendoza, 1 de diciembre de 1779. Protocolo de Escribanos n. 107, fols 118.

23 Presentación de Pascual Suárez al alcalde de $2^{\circ}$ voto, Mendoza, 11 de mayo de 1787. AGN, Sala 9, Tribunales, legajo 160, expediente 10, fols. 58. 
de un paraje escaso de aguas". ${ }^{24}$ A pesar de sus escasos recursos, Pascual se abrió camino para sostener a su familia a través de su trabajo personal: "para mi subsistencia he sembrado mi chacrita de trigo, maíz y legumbres para con ellas alimentar mi triste familia y alguna ocasión conchabándome para el indicado fin”. ${ }^{25}$ En estas tareas cooperaba también su esposa Andrea, la cual procesaba el trigo con su torno de cerner. Entre ambos, Pascual y Andrea, sacaban adelante la familia sobre la base de amor y trabajo.

\section{Sudor del padre por la libertad del hijo}

Tempranamente Pascual Suárez procuró la libertad de su hijo Luis. Este nació el 20 de junio de 1762, cuando sus padres estaban a punto de cumplir su primer año de casados. ${ }^{26}$ El niño creció cerca de sus padres pues, según consta de la evidencia documental, Pascual Suárez se hizo cargo de los gastos de alimento y vestido. Se construyó una relación emocionalmente importante entre padre e hijo, lo cual condujo a Pascual a proponerse la libertad del niño. Planteó la idea a la dueña del mismo, doña María, y ambos resolvieron encargar su tasación a don José Lorenzo de Videla, el cual fijó su precio en \$280. A partir de entonces, Pascual comenzó a pagar a doña María. Por un lado, le entregó \$137 con 4 reales; por otro, trabajó para ella sin cobrar el jornal para ir acumulando una renta para redimir a su hijo; finalmente, Pascual se hizo cargo de los gastos de alimentación y vestido de su hijo, lo cual también era una forma de pagar por adelantado su valor. ${ }^{27}$

El acuerdo entre Pascual Suárez y doña María Corvalán se frustró con motivo de la muerte de ésta. La mujer no dejó constancia escrita de los pagos realizados por Pascual, ni en un recibo ni en sus testamentos. Al contrario, en los dos testamentos que ella redactó después del nacimiento de Luis, se manifestó en el

24 Presentación de Pascual Suárez al alcalde de $2^{\circ}$ voto, Mendoza, 14 de mayo de 1787. AGN, Sala 9, Tribunales, legajo 160, expediente 10, fols. 58-59.

25 Presentación de Pascual Suárez al alcalde de $2^{\circ}$ voto, Mendoza, 11 de mayo de 1787. AGN, Sala 9, Tribunales, legajo 160, expediente 10, fols. 58 y $60 \mathrm{v}$.

26 Bautismo de Luis Suárez, Mendoza, 23 de junio de 1762. Libro de Bautismos n. 6 bis, folio 50. Parroquia Matriz de Mendoza, Archivo del Arzobispado de Mendoza. Allí se consigna que el niño tenía 3 días de edad; sus padrinos fueron Pedro Fernández y María Barros.

27 Pascual Suárez contra testamentaria de doña María Corvalán, Mendoza, 29 de abril de 1786. AHM, Carpeta 286 Documento 37, fols. 1-2. 
sentido exactamente inverso. 28 En el primero, la hacendada declaró poseer el terreno en el cual vivía con su casa, un molino de pan corriente con su sitio respectivo y todo lo plantado, joyas, plata labrada, una colcha de damasco y "alhajas de oro y perlas". ${ }^{29}$ También tenía diez esclavos, entre los cuales se hallaba el hijo de Pascual Suárez. Al definir su destino, doña María señaló que "es mi voluntad se le de a Estanislao Puebla, hijo de doña Petrona, un mulatillo llamado Luis". ${ }^{30}$ En esa época, el pequeño tenía tres años de edad, motivo por el cual lo denominó "mulati1lo". En el segundo testamento (1776), la mujer reiteró esta decisión al establecer que "es mi voluntad se le dé a don Estanislao Puebla un esclavo llamado Luis". ${ }^{31}$ En ese momento, Luis tenía 14 años de edad y ya no se lo nombra como "mulatillo" sino directamente como "esclavo". Doña María vivió todavía una década más. El 19 de noviembre de 1785 redactó un Codicilio en el cual ratificó cláusulas del testamento anterior e introdujo algunas modificaciones que no afectaron la suerte de Luis Suárez. ${ }^{32}$ Doña María falleció poco después, el 9 de diciembre. Fue enterrada en la iglesia de San Francisco con grandes ceremonias en las cuales se emplearon "cruz alta, sacristán mayor, tres capas y cinco posas". 33 Toda la pompa que correspondía a una hacendada. El pleito por la herencia no demoraría en estallar.

Los herederos y sobre todo el albacea, el padre Martín Ladrón de Guevara, manifestaron vivo interés por disponer del muchacho como parte del cuerpo de bienes a repartir. Estanislao Puebla pertenecía a una familia de prósperos viticultores, en la cual se incorporó con un destacado papel en el plano del comercio y el transporte. Trabajó activamente como arriero para trasladar carga entre Mendoza, San Luis y Chile, con recuas de 20 mulas. ${ }^{34}$ En estas condiciones, incorporar la propiedad de un esclavo, valuado en

28 Doña María Corvalán redactó tres testamentos. El primero lo produjo en 1732, y no hizo referencia a Luis pues todavía no había nacido. Testamento de María Corvalán, Mendoza, 10 de julio de 1732. AHM, Protocolo de Escribanos n. 43, fols. 59.

29 Testamento de doña María Corvalán y Castilla, Mendoza, 9 de octubre de 1765. AHM, Protocolo de Escribanos n. 81 fols. 90 v.

30 Testamento de doña María Corvalán y Castilla, Mendoza, 9 de octubre de 1765. AHM, Protocolo de Escribanos n. 81 fols. 90.

31 Testamento de doña María Corvalán y Castilla, Mendoza, 12 de diciembre de 1776. AHM, Protocolo de Escribanos n. 100, fols. 154 v.

32 Codicilio de María Corvalán, Mendoza, 19 de noviembre de 1785. AHM, Protocolo n. 116, fols. 106.

33 Acta de entierro de doña María Corvalán y Castilla, Mendoza, 9 de diciembre de 1785. Libro de Defunciones de la Parroquia Matriz de Mendoza n. 4 b, fols. 145 v.

34 AHM, Manual de Cargo y Data, 1788 y 1789. 
$\$ 280$ era un significativo incremento patrimonial. Tal vez el muchacho no prestaría mucha ayuda para la tarea de arriero; pero la familiaridad de la ruta trasandina facilitaba las cosas para que el mismo Estanislao pudiera llevarlo a Santiago o Valparaíso para venderlo allí o a los tratantes del mercado peruano.

El padre del esclavo se vio alarmado ante esta situación y encontró elementos para sospechar que los nuevos propietarios pretendían venderlo y enviarlo a tierras lejanas, concretamente a Chile cisandino o al Perú. De prosperar este plan, Pascual Suárez quedaría separado para siempre de su hijo, situación que le generaba gran angustia. Ante esto, resolvió iniciar acciones en la justicia. Corría el mes de junio de 1786 y su hijo tenía ya 24 años de edad.

El reclamo de Pascual Suárez era muy concreto: a) su hijo fue tasado en $\$ 280$; b) de esa suma ya había abonado en efectivo $\$ 137$; además se había hecho cargo del vestido y el alimento del mismo durante 24 años; y también había trabajado para doña María sin cobrar su jornal; c) como resultado de estos tres aportes, ya había completado el valor de su hijo, motivo por el cual reclamaba su Carta de Libertad. Su demanda se expresó en los siguientes términos:

Don José Lorenzo lo tasó en \$280. Yo, en esta inteligencia procedía a hacer el pago de dicha cantidad y como mis fuerzas no alcanzaban a hacer prontamente su entero total, le he dado únicamente $\$ 137$; y habiéndole pedido recibo de ellos en ocasión que estaba enferma, me dijo que lo daría luego que convaleciere, habiendo quedado la cosa en ese estado, falleció la señora. ${ }^{35}$

La confusión se habría generado debido a "el lance en que se hallaba la señora al tiempo de otorgar su testamento (motivo por el cual) declaró por esclavo al que era libre". ${ }^{36} \mathrm{Al}$ no poseer recibo ni constancia escrita, las pruebas que Pascual Suárez presentó fueron tres testigos: Victoriano Díaz (30 años), Santiago Corvalán (60 años) y Micaela Munive, mulata, también de 60 años. Los tres eran analfabetos y no firmaron "por no saber"; también eran de extracción social baja; Micaela, por ejemplo, era mulata. Los testigos se presentaron ante la justicia y declararon que Luis fue tasado en \$280; que Pascual había entregado los \$137.4 a doña María; y que también había trabajado para la hacendada, a cuenta de la libertad de su hijo. Santiago Corvalán especificó que "a más de las partidas

35 Declaración de Pascual Suárez, Mendoza, 5 de junio de 1786. AHM, Carpeta 286, Documento 37 fols. 37-37 v.

36 Contestación de Martín Ladrón de Guevara, Mendoza, 22 de julio de 1786. AHM, Época Colonial, Sección Judicial Civil, Carpeta 195, Documento 14, fols. 13 v. 
de dinero que Pascual Suárez dio a doña María Corvalán por el salario de Luis, le dio otras varias partidas a cuenta de la libertad de Luis". ${ }^{37}$ Después de la declaración de los testigos, Pascual Suárez manifestó su posición al respecto:

Siendo constante, público y notorio que yo, con mi sudor y fatiga, por medio de haberme casado en la casa de la señora doña María, he estado contribuyendo con el vestuario y alimento necesarios para mi mujer e hijos, siendo éstos pertenecientes a la obligación de sus amos, con más razón se debe mirar en caridad a la pretensión de un esclavo que pretende libertarse tan solamente por satisfacer a su amo el dominio que tiene en el y no por los beneficios recibidos del amo. 38

Se puso en marcha entonces un desigual pleito entre dos bandos totalmente asimétricos. Por un lado, el padre Martín Ladrón de Guevara, albacea testamentario de doña María Corvalán, sería el defensor de los intereses patrimoniales de los herederos. Por otro, el artesano Pascual Suárez llevaría adelante la causa por la libertad de su hijo. El albacea diseñó una estrategia judicial tendiente a explotar las debilidades sociales, culturales y étnicas de su adversario, fundamentalmente en tres planos: 1) la pobreza de sus redes sociales, formadas sólo por mestizos, mulatos y otros actores del bajo pueblo; 2) el analfabetismo de Suárez y sus testigos, situación que los definía como actores poco familiarizados con el uso de documentos escritos ${ }^{39}$; y 3) la escasez de recursos económicos de Suárez, situación que le impedía pagar fianzas o garantías. La abrumadora superioridad de recursos que ostentaba el padre Martín en estos tres planos sería la base de su estrategia judicial. Por contraste, la causa de Suárez también tenía un punto de vista ventajoso: el hombre luchaba por la libertad de su hijo, mientras que Guevara lo hacía por una cosa, un bien patrimonial de sus mandantes. Y esta supremacía moral, en un mundo que despertaba a las ideas y valores humanos, podía revertir la situación.

37 Declaración de Santiago Corvalán, Mendoza, 29 de abril de 1786. AHM, Carpeta 286 Documento 37, fols. 4.

38 Declaración de Pascual Suárez, Mendoza, 5 de junio de 1786. AHM, Carpeta 286, Documento 37 fols. $37-37 \mathrm{v}$.

39 Martín Ladrón de Guevara firmaba por sí sus escritos judiciales; en cambio, por la contraparte firmaba "José Gabriel Chacón, a ruego de Pascual Suárez". AHM, Juicio de Pascual Suárez por la libertad de su hijo, Mendoza, 11 de julio de 1786 fols. 11, 15 v. Y 19. 
Notificado del pleito, el primer paso del padre Martín fue solicitar el encarcelamiento del esclavo, hasta tanto se definiera el pleito. Y si el padre deseaba evitar esta medida, se le debía exigir una elevada fianza. El notario registró que el sacerdote solicitó:

que dicho Pascual dé fianza lega, llana y abonada para el seguro de las resultas del juicio que intenta seguir, de los costos, costas, jornales y seguridad de la persona del referido Luis y, cuando no, pido sea asegurado en la cárcel pública. ${ }^{40}$

El padre Martín dejaba poco margen de acción para Pascual Suárez: o pagaba esa elevada suma, o su hijo quedaría en la cárcel por tiempo indefinido, a la espera de la finalización del pleito. La modesta situación económica de Pascual no le permitía reunir esa suma, salvo al costo de vender sus escasos bienes y contraer fuertes deudas. Perdería el sitio de su vivienda tendría serios problemas para proveer de sustento a su familia. Pero tampoco estaba dispuesto a aceptar que su hijo fuese enviado al calabozo, dado que la lenta y pesada justicia española podía condenar a Luis a un encierro por tiempo indefinido; y esta situación sería peor que la esclavitud misma. Pascual optó por un tercer camino: la entrega en custodia de su hijo a un vecino confiable de Mendoza: "Yo, como soy un pobre que no tengo sujetos de quien valerme para el efecto, no puedo sin grave dificultad dar dicha fianza, y así me conformo con que se ponga en depósito". ${ }^{41}$

Notificado de la exigencia del padre Martín y la contra propuesta de Suárez, el juez falló a favor de este último y envió al mulatillo Luis Suárez a casa de don Tomás Alvarado para su custodia. ${ }^{42}$ Esta medida disgustó al albacea. Así lo manifestó el padre Martín en su respuesta, donde alegó que: "pedí se sirviese mandar viniese el mulato Luis al cuerpo de bienes donde estaría más asegurado que en poder de ningún depositario, cuya solicitud se ha verificado en grave perjuicio de los interesados sin que se haya otorgado los correspondientes seguros o fianzas que debe proceder a depósito". El padre Martín exigió que Pascual Suárez hiciere algo que, obviamente, estaba imposibilitado de realizar: "Pido se sirva mandar entre al cuerpo de bienes el precitado Luis o se afiance su valor por su padre, Pascual Suárez, con fiador a mi satisfac-

40 Declaración del padre Martín Ladrón de Guevara, Mendoza, 17 de mayo de 1786. AHM, Época Colonial, Sección Judicial Civil, Carpeta 286, Documento 37, fols. 6.

41 Declaración de Pascual Suárez, Mendoza, 17 de mayo de 1786. AHM, Época Colonial, Sección Judicial Civil, Carpeta 286, Documento 37, fols. 10 v.

42 Resolución del juez Lima y Melo, Mendoza, el 11 de julio de 1786. AHM, Época Colonial, Sección Judicial Civil, Carpeta 195, Documento 14, fols. 11. 
ción”. ${ }^{43}$ Estaba claro que Pascual Suárez no podía reunir los recursos suficientes para completar la garantía. El albacea trataba de explotar la débil situación socioeconómica de su adversario. Pero éste apeló a una respuesta moral: solicitó al juez mantener al joven en manos del Depositario para evitar maniobras del albacea. En su declaración judicial, Suárez denunció que "a mi hijo se pretendió transportarlo a otra tierra y que de este modo expirase la justicia". ${ }^{44}$

\section{El padre Martín y su estrategia}

Quedaba entonces definido el escenario: para el vicario eclesiástico, lo que estaba en juego era un objeto, una cosa; pero también se trataba de su carrera: este juicio era una buena oportunidad para demostrar ante los demás hacendados cuyanos, su capacidad y confiabilidad como albacea testamentario. De su celo en defensa del cuerpo de bienes de doña María Corvalán y Castilla, se pondría en evidencia sus capacidades en defensa de la clase dirigente. En cambio, para Suárez, este juicio tenía un significado muy distinto; se trataba de su hijo, su libertad y su vida; era la oportunidad de liberarse de los miedos de una eventual venta de Luis a mercados externos y una separación definitiva de su padre: en caso de ganar, esos miedos quedarían definitivamente sepultados; Pascual podría vivir el resto de sus días junto a su hijo. El padre Martín miraba el conflicto desde una posición de fuerza y abundancia de recursos económicos, lo cual contrastaba con la débil situación de Suárez. El sacerdote era consciente de esta superioridad y estaba dispuesto a explotarla en toda su dimensión. Pero Pascual Suárez estaba sereno y confiaba que había algunas chances de victoria; la primera medida del juez, al entregar a su hijo en custodia en vez de encerrarlo en el calabozo, como pretendía el padre Martín, era un buen indicio.

Frustrado su intento de encarcelar al esclavo, el padre Martín puso en marcha el segundo paso de su estrategia jurídica: impugnar a los testigos de Pascual Suárez. Los tres pertenecían al bajo pueblo, eran amigos y parientes, mestizos y mulatos. Y precisamente esta situación fue la base de la estrategia judicial que diseñaron el albacea y los herederos. En efecto, el padre Martín aseveró que:

43 Réplica de Martín Ladrón de Guevara, Mendoza, 25 de agosto de 1786. AHM, Época Colonial, Sección Judicial Civil, Carpeta 195, Documento 14, fols. 15-15 v.

44 Declaración de Pascual Suárez, Mendoza, 11 de setiembre de 1786. AHM, Época Colonial, Sección Judicial Civil, Carpeta 195, Documento 14, fols. 18 v. 
la información que (Pascual Suárez) ha dado es de ningún valor por ser los testigos de ella tachados por su naturaleza, como lo previenen las leyes, y ser parientes de la mujer de dicho Pascual, y entre tanto no justifica con testigos (válidos) o documentos que acrediten el derecho que solicita, nada tiene vencido en contra de mi parte ni se le puede admitir en juicio al seguimiento de la causa. ${ }^{45}$

Con gran energía, el vicario eclesiástico trataba de imponer la superioridad étnica y socioeconómica de sus defendidos en contraste con la modesta situación de Pascual Suárez, su hijo esclavo y sus ordinarios testigos. "Todos los testigos son tachados, como desde ahora los tacho, así por su calidad como por ser pariente de Luis e interesantes en su libertad (... como por ejemplo...) Victoriano Díaz, mulato y cuñado de Luis". 46

Además de desacreditar por su calidad a los testigos, el padre Martín agravió a la persona de Pascual Suárez. Según el sacerdote, el peón gañán obró "con poca cristiandad, temor de Dios". Por tal motivo "es sospechoso de atrevimiento, digno de la más severa reprensión y castigo". ${ }^{47}$ Más adelante calificó de maliciosa la actitud de Suárez y llegó a solicitar se le niegue el derecho a expresarse. Así lo manifestó el sacerdote al afirmar que los reclamos de Suárez:

son nacidos del engaño con que pretende alucinar al juez para que tenga por realidad su pretensión en descrédito de la testadora por lo que será de justicia le ponga V. M. perpetuo silencio, amonestándole que, de no presentar otros documentos justificativos no se le admitirá más escritos pues sin este preciso requisito solo litiga sobre la conducta de la difunta. ${ }^{48}$

Nótese la demanda del padre Martín al juez: le pidió que pusiera en "perpetuo silencio" al hombre que estaba luchando por la libertad de su hijo. Suárez no podía manifestarse por escrito, dado que era analfabeto; sólo le quedaba el uso de la palabra; pero el vicario pretendía ahogarle también esta posibilidad a través del poder de la justicia. En otras palabras, el representante de la elite trataba de amordazar, segar perpetuamente la voz de un hombre del bajo pueblo que se resistía a ver a su hijo como esclavo.

45 Declaración de Martín Ladrón de Guevara al alcalde de primer voto, Mendoza, 13 de setiembre de 1786. AHM, Época Colonial, Sección Judicial Civil, Carpeta 195, Documento 14, fols. 19-19 v.

46 Contestación de Martín Ladrón de Guevara, Mendoza, 13 de julio de 1786. AHM, Época Colonial, Sección Judicial Civil, Carpeta 195, Documento 14, fols. 13.

47 Contestación de Martín Ladrón de Guevara, Mendoza, 13 de setiembre de 1786. AHM, Época Colonial, Sección Judicial Civil, Carpeta 195, Documento 14, fols. 13 v.

48 Contestación de Martín Ladrón de Guevara, Mendoza, 13 de setiembre de 1786. AHM, Época Colonial, Sección Judicial Civil, Carpeta 195, Documento 14, fols. 13 v.14. 
La exigencia de pruebas escritas fue otro de los pilares con que el albacea trató de sacar ventaja de la supremacía sociocultural de su parte. Los documentos escritos favorecían su causa. Su parte poseía un libro de cuentas, en el cual figuraban los gastos de la hacienda; y allí constaba que Pascual Suárez, efectivamente, había trabajado al servicio de doña María Corvalán; también aparecía el salario fijado. Pero según el padre Martín, no se indicaba allí que ese dinero se hubiese afectado a comprar la carta de libertad de Luis. Así lo sostuvo el vicario en la petición judicial: "Las partidas que dice (Pascual Suárez) dio a cuenta de la libertad de su hijo, constan en el citado cuaderno ser dadas por cuenta de su salario". ${ }^{49}$ Paralelamente, el albacea señaló que no existía constancia escrita de un contrato entre doña María y Pascual Suárez; tampoco había documentación fehaciente sobre el plan de compra de la Carta de Libertad. En este sentido, el debate tendía a elevar el valor del testamento como documento indiscutible para fundar el derecho. Según el padre Martín, el documento citado:

verifica la esclavitud de dicho Luis y de no haber sido entregadas las partidas de plata a cuenta de libertad, sino de salarios, la cláusula testamentaria de la referida señora en que declara dejar el mulatillo Luis para don Estanislao Puebla, cuando era constante que si hubiese habido el contrato que se supone dijera en la cláusula que, en caso de no cumplir Pascual con lo que habían tratado, declaraba a Luis por esclavo y lo dejaba por tal a don Estanislao Puebla; pero dejarlo absolutamente por su esclavo sin declaración alguna, evidencia no haber habido el contrato figurado y que las partidas del cuaderno son ciertas y legítimas como en el se expresan sin que esto se oponga a que se le rebaje de lo entregado el vestuario y mantención, esto es haciendo constar haber pagado enteramente todos los salarios mensuales desde el tiempo que se hizo cargo de él.50

El proceso judicial avanzaba en la definición de las armas que poseía cada parte. Del lado del vicario eclesiástico, representante de la elite, estaban los documentos testamentarios y contables de uno de sus miembros, pruebas escritas, por cierto. En cambio del lado de Pascual Suárez sólo había testimonios orales de mulatos y mestizos, pertenecientes a su mismo grupo. El alba-

49 Contestación de Martín Ladrón de Guevara, Mendoza, 13 de setiembre de 1786. AHM, Época Colonial, Sección Judicial Civil, Carpeta 195, Documento 14, fols. 11 v12.

50 Contestación de Martín Ladrón de Guevara, Mendoza, 13 de setiembre de 1786. AHM, Época Colonial, Sección Judicial Civil, Carpeta 195, Documento 14, fols. 12 v. 
cea testamentario trataba de llevar el juego al sector donde tenía ventajas, es decir, el plano de la cultura escrita. Pero era insólito pretender que un gañán analfabeto tuviera respaldo documental de los acuerdos que había alcanzado con sus patrones. El padre Martín exigía este tipo de pruebas porque sabía que Pascual Suárez no podía tenerlas. Como tampoco tendría testigos de extracción social alta.

El sacerdote también trató de asumir la defensa de valores morales. Si Pascual luchaba por la libertad de su hijo, el albacea lo hacía por el prestigio de la testadora. Su causa era evitar el descrédito de doña María Corvalán y Castilla. En una sociedad que discriminaba a las mujeres vivas, surgía un notable interés por defender la credibilidad de una mujer difunta. La sociedad mendocina sabía y aceptaba que uno de los más encumbrados empresarios y políticos de la época tuviera a su esposa en una cárcel privada, dentro de su propia hacienda, sin que nadie hiciera nada por ello. Eso sucedía porque la mujer en cuestión, doña Tomasa Ponce de León, estaba viva. Pero por una mujer difunta sí era legítimo luchar en defensa de su honor.

\section{La justicia colonial y sus sentencias}

El pleito iniciado por Pascual Suarez por la libertad de su hijo Luis se inició en Mendoza. Pero muy pronto, el mulato advirtió que sus chances eran nulas en la justicia local. La influencia de la familia Corvalán y Castilla era tan abrumadora que no tenía mayor sentido esperar un resultado positivo. La única posibilidad era lograr un cambio de jurisdicción para que el juicio se ventilara lejos de la influencia de los hacendados y clérigos cuyanos. El horizonte de Pascual Suárez era lograr el traslado de la causa desde Mendoza hacia Buenos Aires. Allí funcionaba la flamante Real Audiencia, recientemente instalada. En efecto, en el marco del proceso modernizador del imperio español, impulsado por Carlos III, en la década de 1780 se crearon tres nuevas Reales Audiencias en América Hispánica: Caracas (1783), Buenos Aires (1783) y Cuzco (1787). La constitución de estos organismos judiciales abrió nuevas posibilidades para la administración de justicia. Y desde la perspectiva de Pascual Suárez, estos tribunales ofrecían más garantía que los locales. Allí orientó entonces su estrategia para tratar de liberar a su hijo. 
El reclamo de Pascual y Andrea llegó a Madrid. El rey de España, Carlos III, ordenó que se diera curso a su reclamo a través de la Real Provisión del 30 de octubre de 1787.51 A través de este documento, la Corona aceptó la apelación y ordenó se trasladasen los antecedentes de la capital cuyana a la sede de la Real Audiencia de Buenos Aires. Para evitar que los tiempos se dilataran excesivamente, Pascual Suárez viajó a Buenos Aires para recoger la Real Provisión y llevarla a Mendoza. Estos viajes resultaban abrumadoramente costosos y largos en esos tiempos (las carretas demoraban más de tres meses en ir y venir entre ambas ciudades). Pascual calculaba que, con su diligencia, lograría que, en poco tiempo, el expediente se trasladara a Buenos Aires y la causa avanzaría con mayor celeridad. $Y$ en un principio, tuvo motivos para esperanzarse. Tras recibir este documento, el 9 de enero de 1788 el alcalde de segundo voto de Mendoza, don Francisco Segura, labró el acta por la cual acusaba recibo de la Real Provisión y se comprometía solemnemente a acatarla. El documento señalaba textualmente "habiendo visto, oído, leído y entendido la antecedente Real Provisión, puesto de pie, y puesta sobre su cabeza, dijo que la obedecía y obedeció". 52 Con este documento, Pascual calculaba tener pronto el expediente en su poder para trasladarlo personalmente a la Real Audiencia y entonces avanzar. No obstante, todas sus expectativas se vieron defraudadas.

En efecto, los tiempos se fueron alargando. Pasaron los meses y la documentación no salía de Mendoza. Frustrado en sus expectativas, Pascual manifestó su disconformidad ante la justicia y solicitó se le entregasen los expedientes, tal como había ordenado el Rey. No obstante ello, el alcalde Segura le contestó "no ha lugar a la entrega de autos que solicita". ${ }^{53}$ El motivo era que, para mayor seguridad, se confiarían los papeles a un reputado abogado de la Real Audiencia de Santiago de Chile. Siguieron una serie de acciones jurídicas que fueron engrosando el expediente a costa de dilatar cada vez más los tiempos. Luego apareció el abogado. Era el doctor don José Agustín de Sotomayor, el cual se incorporaba a la causa en calidad de asesor letrado. 54

51 Real Provisión de Carlos IV, 30 de octubre de 1787. AGN, Sala 9, Tribunales, Lagajo 160, Expediente 10, fols. 63-69.

52 Acta de acatamiento a la Real Provisión. Mendoza, 7 de enero de 1788. AGN, Sala 9, Tribunales, Legajo 160, Expediente 10, fols. 69-69 v.

53 Notificación del alcalde a Pascual Suárez, Mendoza, 31 de marzo de 1788. AGN, Sala 9, Tribunales, Legajo 160, Expediente 10, fol. $70 \mathrm{v}$.

54 Nota de remisión del expediente al doctor Sotomayor, Mendoza, 9 de mayo de 1791. AGN, Sala 9, Tribunales, Legajo 160, Expediente 10, fols. 108-108 v. 
El advenimiento de Sotomayor a la causa significaba fortalecer el poder de la parte esclavista del pleito. ${ }^{55}$ En efecto, el flamante abogado pertenecía a una de las "tres casas reinantes de Cuyo", junto con los Martínez de Rosas y los Corvalán. Eran las familias que controlaban los principales resortes del poder político y socioeconómico de la región, debido, en buena medida, a las estrechas relaciones políticas y parentales que cultivaron entre ellas. Tal como se ha señalado oportunamente, José Agustin Sotomayor estaba casado con doña María Josefa Corvalán Rosas, sobrina de doña María Corvalán, ama de Luis Suárez. Por lo tanto, la familia era juez y parte de la misma causa. Por este camino se preparó el desenlace. El 2 de setiembre de 1791 la justicia rechazó la demanda de Pascual por entender que las refutaciones del padre Martín estaban conforme a derecho. La sentencia fue redactada en los siguientes términos:

En la causa que ante mi ha pendido, y pende entre partes de la una Pascual Suárez actor demandante y de la otra doña Petrona Corvalán sobre pretender aquel la libertad de su hijo Luis, y lo demás contenido en los autos. Fallo atento a los Autos, y méritos del proceso a que en lo necesario me refiero, que el enunciado Pascual Suárez no probó su acción, y demanda como probar le convenía la doy por no probada y que doña Petrona Corvalán justificó sus excepciones, y defensas como justificar le convenía. Las doy por bien justificadas, en cuya consecuencia debo de declarar y declaro, que los $\$ 117$ con 4 reales, que resultan de las partidas testimoniadas a fojas 36 deban tenerse, y reputarse como dadas a cuenta de los jornales que el referido Pascual se obligó a prestar por el servicio de su hijo Luis a la finada doña María Corvalán su señora, y no como exceso de aquellos a cuenta de la libertad debiendo doña Petrona abonar el vestuario y alimentos, que el mencionado Pascual haya contribuido a su hijo Luis satisfaciendo este al mismo tiempo los jornales adeudados con arreglo al Decreto a fojas 5 vuelta, y por esta mi sentencia definitivamente juzgando su condenación de costas con dictamen de Asesor Letrado así lo pronunció mandó y firmó. ${ }^{56}$

55 José Agustín Sotomayor y Videla nació en Mendoza, hijo del maestre de Campo don José Sebastián Sotomayor y de doña María Isabel de Videla y Salazar. Su acomodada familia lo envió a estudiar fuera de Mendoza. Primero viajó a Córdoba donde fue alumno del Real Colegio Monserrat y de la Real Universidad de Córdoba del Tucumán. Posteriormente se trasladó a Santiago de Chile y entre 1780 y 1786 estudió leyes en la Real Universidad de San Felipe. Montt, Luis Lira. Estudiantes cuyanos, tucumanos, rioplatenses y paraguayos en la Real Universidad de San Felipe y colegios de Santiago de Chile, 1612-1817. Historia, 14, Santiago de Chile, 1979, p. 261-262.

56 Sentencia firmada por José Agustín Sotomayor, Mendoza, 2 de setiembre de 1791. Juicio Civil contra testamentaria de doña María Corvalán, sobre la libertad del cria- 
Con esta sentencia, la Justicia avalaba los criterios del albacea. Los testigos presentados por Pascual Suárez quedaban tachados, por su falta de calidad (eran mulatos y criollos pobres). Con ellos no alcanzaba para acreditar el reclamo de aquel trabajador. La justicia colonial desenmascaraba toda su fuerza a favor del sistema esclavista y de una sociedad fuertemente estamentada, donde no había igualdad de derechos ni para los hombres libres. Se revelaba la alianza entre el armazón jurídico, los hacendados y el clero, a la vez que se exhibía escasa sensibilidad ante el dolor humano de los sectores subordinados de la sociedad, sobre todo los esclavos, los mulatos y el bajo pueblo chileno. Estas medidas reaseguraban el orden jerárquico de la hacienda, en particular, y de la sociedad, en general. La justicia abogaba por una sociedad segmentada, con diferencias socioeconómicas claras y francas. Pascual Suárez quedaba, además, condenado a pagar las costas del juicio, lo cual significaba perder buena parte de sus escasos bienes. Con esta medida se intentaba desalentar los reclamos del bajo pueblo, que pretendía cuestionar el orden social vigente. Además, la burocracia judicial les obligó a dejar en garantía una serie de bienes que eran sumamente importante para los Suárez: la olla de hierro, una batea de madera, una caja y, fundamentalmente, el torno de cernir. Estos fueron dejados en depósito, por orden judicial. 57

Todo parecía perdido, una vez más, para los Suárez. No obstante, no se rindieron. Pascual impugnó el fallo, alegando una serie de irregularidades, entre ellas que no se tuvo en cuenta su apelación ante la Real Audiencia de Buenos Aires, y el nepotismo manifiesto en el aparato judicial. En efecto, el padre del esclavo denunció en un escrito que "el asesor nombrado (Agustín Sotomayor) es parte apasionada de doña Petrona (Corvalán) y presenta relación de parentesco y afinidad". Con estos antecedentes, Pascual afirmaba que la sentencia debía ser considerada nula.58 Pero la única forma de avanzar era sustraer el proceso del aparato judicial local, traspasada como estaba de las influencias de los Corvalán. Pascual se apoyó en el Procurador de Pobres de la Real Audiencia de Buenos Aires e insistió en su demanda, hasta lograr una nueva Real Provisión. A todo esto, en Madrid, Carlos III había muerto

do Luis Suárez. AHM, Época Colonial, Sección Judicial, Carpeta 195 documento n. 18, sin numeración; contando desde el final del documento fols. 7 y 8.

57 Declaración de doña Patrona Corvalán al alcalde de $1^{\circ}$ voto, Mendoza, 7 de julio de 1796. Suárez, Pascual contra Petrona Corvalán sobre devolución de unos bienes que ésta le tiene embargados. AHM, Época Colonial, Sección Judicial Civil, Carpeta 196 documento 19 fols. 3.

58 Presentación de Pascual Suárez, Mendoza, 28 de setiembre. 
(1788) y fue sucedido por Carlos IV. Pero el nuevo rey coincidió con su antecesor en el sentido de acoger como justa la solicitud del mulato. Por ello escribió al alcalde de Mendoza para ordenarle que "remitáis cerrados y sellados de mano de vuestro presente escribano de Cámara a la dicha nuestra Real Audiencia Pretorial". ${ }^{59} \mathrm{La}$ Real Provisión llegó a Mendoza el 23 de febrero de 1792 y fue inmediatamente acatada por el alcalde, con la mayor teatralidad: "habiéndola su servidor oído, leído y entendido, puesto en pie, besádola y puesta sobre su cabeza, dijo que la obedecía y la obedeció como a letras y carta del nuestro Rey y Señor". ${ }^{60}$

El amor de Pascual y Andrea por su hijo había alcanzado un logro notable: dos reyes de España tomaron acción en el pleito, y arbitraron medidas para agilizar los trámites, a través de sendas Reales Provisiones. Y la apacible ciudad de Mendoza vio como su autoridad municipal debía besar un documento en el cual figuraba el nombre de un esclavo y la firma del monarca. Pascual y Andrea podían sentirse satisfechos de estos honores. Pero este era un premio bastante pobre para un pleito que estaba cerca de cumplir seis años.

A esta altura, las energías de Pascual se estaban agotando, a la vez que se le abrieron otros frentes y persecuciones. Por motivos que no ha sido posible conocer, el hombre estuvo encerrado en la cárcel, y luego, permaneció largo tiempo postrado por sus enfermedades. En efecto, un año después, Pascual todavía no podía viajar a Buenos Aires para continuar con el juicio. Su hijo explicó que: "esta diligencia se ha demorado a causa de la grave y notoria enfermedad del dicho mi padre en que se haya postrado sin esperanza de que se levante y de seguirse mayor dilación en el Auto a causa de no poder personalmente comparecer en aquel Regio Tribunal a usar del derecho que se le permite".61

En el mismo documento se explica que Pascual Suárez carecía de medios para hacerse representar en Buenos Aires por apoderados o abogados, dada su condición de "pobre de solemnidad". Por tal motivo, Luis pidió permiso para viajar a Buenos Aires y continuar con el pleito. Después de largas dilaciones, el comandante de

59 Real Provisión de Carlos IV, 16 de noviembre de 1791. AGN, Sala 9, Tribunales, Lagajo 160 Expediente 10 fols. 11 v-113. AGN, Sala 9, Tribunales, Legajo 160 Expediente 10 fols. $111 \mathrm{v}-113$.

60 Acta del alcalde Manuel de Ochoa, Mendoza, 23 de febrero de 1792. AGN, Sala 9, Tribunales, Legajo 160, Expediente 10 fols. 115 v-116.

61 Nota de Luis Suárez a la Real Audiencia, Mendoza 11 de junio de 1792. AHM, Época Colonial, Sección Judicial, Carpeta 195 documento $n^{\circ}$ 18, sin numeración; contando desde el final del documento, folio 2. 
Armas de Mendoza le otorgó la autorización el 12 de abril de 1794.62 Habían transcurrido seis años y dos meses desde la llegada de la Real Provisión de Carlos III a Mendoza y recién entonces, un miembro de la familia podía viajar a Buenos Aires para llevar adelante la nueva etapa del pleito.

La estadía de Luis en Buenos Aires sería larga y complicada. Para sustentarse se empleó como trabajador rural "en la chácara del doctor Paz", por un salario de \$6 mensuales. Con estos ingresos y el respaldo escrito de su empleador, Luis logró también establecer las fianzas exigidas por la justicia con "los conchavos que devengue, en la parte que de ellos quede libre, deducidos los renglones del tabaco, almuerzos y vestuario y menudos gastos de su pleito". ${ }^{63}$ Por otra parte, los propietarios mendocinos no estaban de acuerdo con el desplazamiento de Luis a Buenos Aires, e hicieron todo lo posible para hacerlo regresar cuanto antes a sus funciones de esclavo. En efecto, su amo, don Estanislao Puebla, viajó personalmente a Buenos Aires y lo denunció como prófugo. Se presentó ante las autoridades para afirmar que Luis Suárez debía regresar inmediatamente a Mendoza a cumplir con el servicio debido a sus amos. Y exigió que se le entregaran tanto los salarios que hubiese ganado en Buenos Aires, como los jornales no trabajados durante todo el tiempo de estadía en esta ciudad. Esta presión generó nuevos pleitos que se ventilaron en la Real Audiencia, hasta que Luis Suárez logró que lo dejaran tranquilo.

Mientras tanto su hermana, María Dominga, a pesar de ser esclava, se dedicó a cuidar a su padre. Con sus escasos recursos y su enorme amor, ella se hizo cargo de "la asistencia en la enfermedad y de un año que estuvo en la cárcel donde yo lo mantuve". ${ }^{64}$

La situación de Dominga Suárez merece un breve comentario. Su ama era doña Francisca Puebla, hermana de Estanislao y, por lo tanto, hija de Juan Martín de Puebla y bisnieta del célebre capitán Juan de Puebla y Reinoso. Algo especial corría por las venas de doña Francisca; algo especial heredado de sus ancestros, seguramente; y ello la movería a ser particularmente generosa con su esclava Dominga. Primero, con los permisos que le dio para que

62 Concesión de licencia a Luis Suárez, Mendoza, 12 de abril de 1794. AGN, Sala 9 37-84, legajo 160, expediente 10, fols. 120 .

63 Presentación de Francisco de Alba, procurador de pobres, a nombre de Luis Suárez, pardo esclavo, pobre y miserable. Buenos Aires, 26 de noviembre de 1794. AGN, Sala 9 , legajo 160, expediente 10, fols. 125.

64 Declaración de María Dominga Suárez, Mendoza, 12 de junio de 1816. Don Luis Suárez con doña Dominga Suárez por derecho a herencia. AHM, Época Independiente, Sección Judicial Civil, Letra S 1812-1860, legajo 2, carpeta 114. 
cuidara a su padre y facilitara los trámites de su hermano en Buenos Aires en procura de la libertad. Y después, doña Francisca tomaría otras decisiones, como veremos más delante.

La familia fundada por Pascual Suárez se distribuyó las tareas para revertir su destino. El padre enfermo quedó al cuidado de su hija Dominga. Luis viajó a Buenos Aires a dar la batalla final. El pleito se alargó durante cuatro años más, y no hizo más que ratificar el criterio del aparato judicial colonial. En efecto, la Real Audiencia de Buenos Aires confirmó el dictamen anterior. En su sentencia final, los oidores resolvieron que Luis Suárez era esclavo de la familia Corvalán y Castilla; por lo tanto debía volver con sus amos. Además, lo condenó a pagar los jornales perdidos durante su ausencia. ${ }^{65}$

A pesar de todo, los Suárez insistieron con su reclamo de libertad, hasta que finalmente se logró un acuerdo con doña Petrona. A cambio de un aporte mayor de dinero, los propietarios del esclavo aceptaron otorgarle la libertad.66 Para Pascual Suárez, esta era la única opción que le quedaba, debido a la asimetría de fuerza entre los bandos en pugna; pero el arreglo era injusto. Así lo manifestó Pascual Suárez en un escrito que presentó poco después en la justicia de Mendoza. Allí afirmó que el pleito con doña Petrona se había "transado y evacuado en la ciudad de Buenos Aires". El concepto "transar" se usaba en América para significar "transigir, ceder, llegar a una transacción o acuerdo".67 A su vez, "transigir" significa "consentir en parte con lo que no se cree justo, razonable o verdadero, a fin de acabar con una diferencia", o bien "ajustar algún punto dudoso o litigioso, conviniendo las partes voluntariamente en algún medio que componga y parta la diferencia de la disputa".68 Finalmente, Pascual y Andrea habían logrado el objetivo de liberar a su hijo. Pero el precio resultaba más alto de lo pensado. Asimismo, todavía les quedaban algunas desagradables sorpresas al respecto.

65 Pascual Suárez sobre la libertad de su hijo Luis contra doña Petrona Corvalán, Mendoza, año 1786. Archivo General de la Nación (Buenos Aires), Tribunales, legajo 160, expediente 10, sala 9. 37-8-4.

66 No ha sido posible hallar la Carta de Libertad de Luis Suárez. Pero ella se infiere de otros documentos, entre ellos, el censo parroquial del 27 de agosto de 1802, en el cual Luis Suárez figura como "libre", lo mismo que su esposa Norberta Fredes y sus dos hijos Isabel Fredes y Matías Suárez. Censo parroquial año 1802. Cuadernillo ${ }^{\circ}$ 11, 654. Archivo del Arzobispado de Mendoza.

67 RAE: 2, 2008.

68 RAE: 2, 2010. 
Terminado el largo pleito con doña Petrona Corvalán, Pascual y Andrea intentaron recuperar los bienes que habían dejado embargados para afianzar el pleito. No obstante ello, la hacendada no le brindó una respuesta satisfactoria. Pascual debió acudir a la justicia para obtener sus enseres, particularmente su preciado torno de cernir. El 4 de mayo de 1796 presentó una nota formal en reclamo de sus pertenencias; al no recibir respuesta dentro de los plazos previstos, el 6 de junio elevó una segunda nota, en la cual reiteraba el pedido y llegaba a acusar a la hacendado de estar "en rebeldía" por dilatar la devolución de sus bienes. ${ }^{69}$ Un mes más se tomó la hacendada para contestar la nota. Y su respuesta no hizo más que desorientar a Pascual Suárez:

Aunque tengo noticia del embargue de bienes que mencionó en su escrito, sólo puedo decir que, en el particular que él se hizo por orden del señor Juez de la causa, quien dispuso de ellos, habiendo quedado en mi poder sólo una batea que tomé en pago de $\$ 8$ y di para la compulsa de autos: de todos los otros no tengo noticia, que un torno lo compró doña Tomasa Escalante, cuyo producto oí decir que lo tomó el escribano don Pablo Videla en pago de sus derechos, y una caja y olla de hierro también he oído que se le dieron a don José Lagos por lo que se le debía de sus actuaciones.70

La respuesta de doña Petrona revelaba, una vez más, la forma de funcionamiento de los estamentos privilegiados del Antiguo Régimen Colonial; particularmente la concepción patrimonialista de los cargos públicos. Con notable impunidad, los miembros del círculo del poder se habían repartido los escasos bienes de un miembro del bajo pueblo.

El clima familiar se tornaba cada vez más frustrante. La obtención de la libertad de Luis había significado exprimir casi a fondo los magros recursos de la familia Suárez y la condenaban a sufrir todavía más privaciones. La carga y el infortunio parecían demasiado grandes. Andrea Corvalán, no pudo salir del pantano de tristeza y falleció poco después. El entierro se hizo con modestia, con cruz baja. Se levantó un acta escueta para dejar constancia: "En la Iglesia de Santo Domingo, se enterró con cruz baja el

69 Demanda de Pascual Suárez, Mendoza, 6 de junio de 1796. Suárez, Pascual contra Petrona Corvalán sobre devolución de unos bienes que ésta le tiene embargados. AHM, Época Colonial, Sección Judicial Civil, Carpeta 196 documento 19 fols. 2.

70 Declaración de doña Patrona Covalán al alcalde de $1^{\circ}$ voto, Mendoza, 7 de julio de 1796. Suárez, Pascual contra Petrona Corvalán sobre devolución de unos bienes que ésta le tiene embargados. AHM, Época Colonial, Sección Judicial Civil, Carpeta 196 documento 19 fols. 3 . 
cuerpo de Andrea mulata esclava de doña Petrona Corvalán; fue casada con Pascual Suárez; recibió los santos sacramentos. Y para que conste lo firmé. Doctor Ambrosio Joseph de Ochoa".71

Entre las paredes del templo de la Orden de Predicadores quedaba el cuerpo de la mulata Andrea. Con ella se terminaba una vida que, durante 35 años, se orientó hacia una utopía, un lugar mejor, que era la libertad de su hijo y el bienestar de la familia. Se logró el primer objetivo, pero con un fuerte retroceso en el segundo. La alianza de hacendados, clérigos, capitulares y oidores era una muralla impenetrable en defensa del orden social. Andrea, junto a su esposo Pascual, trató de luchar contra este orden que privilegiaba a una minoría y excluía a las capas sociales más populares. Ella no pudo actuar judicialmente porque su condición de esclava no se lo permitía. Pero acompañó en todo momento a su marido; estuvo a su lado hasta el fin de sus días. Ella amó a su marido y a sus hijos; luchó por ellos y junto ellos. Hasta morir de amor.

\section{De víctima a victimario}

A la muerte de Andrea Corvalán le siguió poco después la de Pascual Suárez. Ambos se perdieron de ver los grandes acontecimientos que vendrían más tarde, que le habrían causado una tristeza mucho más profunda. Desde el punto de vista de las emociones, lo que vino después era muy fuerte.

La actitud de Luis Suárez, luego de obtener la libertad, estuvo lejos de corresponder a la solidaridad familiar que se hubiera esperado. Al contrario, trató de aprovechar las ventajas de la condición de libre en detrimento de sus familiares que todavía permanecían en la esclavitud, particularmente su hermana. En efecto, tras el fallecimiento de Pascual Suárez, se realizó el entierro, los funerales y las misas de costumbre. Estos homenajes fueron pagados por su hija Dominga, que todavía era esclava, y sin aportes de Luis. El alcalde García llegó a ordenarle que le reembolsara esos gastos a su hermana, pero sin éxito. 72

71 Acta de defunción de Andrea Corvalán, Mendoza, 19 de diciembre de 1796. Libro de defunciones de la Parroquia Matriz de Mendoza 1789/1810, folios 72 y 72v. En el margen izquierdo del acta aparece: Andrea esclava - Derechos 18 reales.

72 Declaración de María Dominga Suárez, Mendoza, 12 de junio de 1816. Don Luis Suárez con doña Dominga Suárez por derecho a herencia. AHM, Época Independiente, Sección Judicial Civil, Letra S 1812-1860, legajo 2, carpeta 114, folio 16. 
Poco después se generó otro conflicto debido a la partición de la herencia. Esta era muy modesta, pues apenas ascendía a \$100. Dominga esperaba recibir una parte, al menos para pagar los gastos que ella había solventado en el cuidado y entierro de su padre. No obstante ello, la reacción de su hermano fue de oposición cerrada. Luis Suárez trató de explotar la ventaja jurídica que tenía en su condición de libre, para quedarse con la totalidad de la herencia con exclusión a sus hermanos María Dominga y Roberto.73 Se produjo entonces un singular juicio entre los hermanos por los bienes de sus padres. La argumentación de Luis Suárez en defensa de sus derechos se fundaba, principalmente, en los privilegios que ahora él tenía, por la superioridad de su condición de libre por sobre la de su hermana esclava. El escrito señalaba lo siguiente:

Luis Suárez natural de esta ciudad ante Vuestra Merced en la forma que mejor haya lugar en derecho me presento y digo: que mi hermana Dominga Suárez, esclava de doña Francisca Puebla, me ha demandado verbalmente ante $\mathrm{V}$. solicitando adquirir derecho a la herencia que legítimamente me cupo por fallecimiento de mi padre Pascual Suárez por ser el (único) heredero que al tiempo de su fallecimiento estaba hábil por la ley. Con todo estamos en el caso de que la dicha, siendo esclava, no puede comparecer en juicio sin gozar de la plena libertad que corresponde por rigor de Justicia. ${ }^{74}$

A través de este documento, Luis Suárez demostró que su lucha por la libertad no había sido por un principio; no estaba cuestionando el sistema, sino que quería cambiar el lugar que él, personalmente, tenía dentro de ese orden social para luego, aprovecharlo en beneficio propio. En este caso, el liberto pretendía explotar los privilegios que había adquirido en detrimento de su hermana. Como ella, de todos modos, trató de defender sus derechos a la herencia paterna, la reacción de Luis Suárez fue enérgica: exigió a la justicia que no atendiera los reclamos de su hermana por no tener derecho a ellos. En otra presentación, Luis manifestaba, con arrogancia, que la justicia debía ser enérgica contra su hermana, alegando que

sin embargo de esta exposición se sirvió V. decretar con fecha $1^{\circ}$ de Agosto del corriente año, ordenando que la dicha mi hermana Do-

73 Don Luis Suárez con doña Dominga Suárez por derecho a una herencia. Mendoza, $1^{\circ}$ de agosto de 1815 hasta el 11 de noviembre de 1816. AHM, Época Independiente, Justicia Civil, Carpeta n. 114, Judicial Civil, Letra S, 1812/1860, Legajo n. 2.

74 Declaración de Luis Suárez, Mendoza, 1 de agosto de 1815. Don Luis Suárez con doña Dominga Suárez por derecho a herencia. AHM, Época Independiente, Sección Judicial Civil, Letra S 1812-1860, legajo 2, carpeta 114, folio 1 y 1v. 
minga presentase documento que acreditase la libertad de su comparecencia; pero lejos de cumplir con tan expreso mandato... Parece increíble hayan personas que sin temer ser descubiertas en sus tramas y enredos (máxime cuando se dirigen contra los Juzgados) se abandonan a tal extremo que ni lo mas sagrado respetan, no temen los más serios castigos que saben debe recaerles. Tal es el engaño y malignidad depravada con que mi hermana (o mejor diré quien la dirige) ha pensado engañar a la rectitud de $\mathrm{V}$, pero estoy cierto que por ella será guardada mi justicia, y que severamente será reprendida la citada mi hermana para que se abstenga en lo sucesivo de semejantes procedimientos de ilegalidad, inconsecuencias y falta de cumplimiento a los mandatos judiciales. 75

Asombra constatar la valoración que Luis Suárez hace de la acción de su hermana en defensa de sus intereses. Para Luis, Dominga actúa con "engaño y malignidad depravada". Es decir, le niega totalmente a la esclava, los derechos de reclamar algo. La arrogancia de esta declaración hace acordar el tono que usaba el padre Martín Ladrón de Guevara para litigar contra las pretensiones de Luis Suárez, cuando éste se hallaba en la condición de esclavo.

Los nuevos tiempos facilitaron las cosas para Dominga. Sobre todo porque la revolución de 1810 determinó el final de la colonia y la circulación de nuevas ideas. En 1813 la Asamblea Nacional había establecido la libertad de vientres. Mientras tanto, en Mendoza, José de San Martín y Bernardo O'Higgins preparaban el ejército de los Andes para terminar con la dominación de los godos en Chile. Poco a poco se avanzaba hacia un nuevo modelo de sociedad. En este contexto, el 22 de junio de 1815, doña Francisca Puebla, hija de Juan Martín de Puebla y bisnieta del capitán Juan de Puebla y Reinoso, le extendió la Carta de Libertad a María Dominga Suárez. ${ }^{76}$ Con este documento, la mulata pudo seguir adelante el pleito contra su hermano. En su presentación entregó más detalles sobre la vida de la familia:

Ambos nacimos esclavos, y ambos hemos adquirido la libertad, con la diferencia que a él lo libertó mi padre con dinero que adquirió con su sudor, y a que yo tengo derecho por la representación que he adquirido. (...). Yo no distaría de que Luis llevase toda la herencia que queda por muerte de mis padres, si él estuviera a la misma delibera-

75 Declaración de Luis Suárez, Mendoza, 20 de noviembre de 1815. Don Luis Suárez con doña Dominga Suárez por derecho a herencia. AHM, Época Independiente, Sección Judicial Civil, Letra S 1812-1860, legajo 2, carpeta 114, fols. 4 y 4v.

76 Carta de Libertad otorgada por Francisca de Puebla a su esclava Dominga, Mendoza, 22 de junio de 1815. AHM, Protocolo de Escribanos n. 173 fol. 65. 
ción del Alcalde García en que ordenó que me abonase los gastos de entierro de los funerales o misas, la asistencia en la enfermedad y de un año que estuvo en la cárcel donde yo lo mantuve, y la mitad del valor en que se libertó el mismo Luis. Todo asciende a otro tanto de lo que importa el terreno o herencia de la disputa. Sería la cosa más terrible que se hubiese oído en nuestro siglo el que se me privase de la herencia y de los gastos que yo hice en mis finados padres, cuando Luis no ha hecho otra cosa que disfrutar de los bienes y no haber auxiliado a su padre con un jarro de agua ni en su prisión, ni en su enfermedad, como que no se hallaba en esta ciudad en aquellos tiempos de aflicción para mí, sino en Buenos Aires adonde fue al pleito de su libertad que se le negaba por que mi Padre no había acabado de satisfacer el total de su importe. Concluyo pidiendo que por ser punto puramente de derecho, y ser la herencia de tan poca entidad que no llegara al valor de $\$ 100$, se digne costar este asunto en el presente estado. ${ }^{77}$

Este documento entrega un dato clave para comprender la trama. En primer lugar, la lucha por la libertad de Luis Suárez no había sido una tarea personal de su padre, sino una causa familiar; todos habían participado en la epopeya, y se distribuían solidariamente el trabajo. Para que Luis pudiese viajar a Buenos Aires, su hermana se hizo cargo del padre. Había un lazo fuerte en la familia para avanzar en una dirección determinada y lograr un objetivo común. Pero una vez lograda la meta, esa solidaridad se rompió. Sobre todo por el actor que se vio más favorecido, pues, en vez de retribuir a la familia para devolver la ayuda recibida, Luis se apoyó en la situación de poder obtenida por el trabajo colectivo, para sacar ventajas con respecto a los de su misma sangre.

De todos modos, las apreciaciones de Luis Suárez resultaron inconsistentes con la nueva realidad social que se comenzaba a abrir a partir de la Revolución. Su experiencia sobre el funcionamiento de las instituciones judiciales correspondían al Antiguo Régimen Colonial; y con estos conceptos en mente, Luis calculó que podía obtener provecho. No obstante ello, la justicia pos revolucionaria era, al menos, algo diferente. En efecto, la sentencia resultó favorable a su hermana, de acuerdo al documento redactado en los siguientes términos:

Conformado con el precedente dictamen, tendré por definitiva en esta causa; con declaración especial de que la presentada Dominga Suárez, se tendrá por igual parte en la herencia que ha percibido su

77 Declaración de María Dominga Suárez, Mendoza, 12 de junio de 1816. Don Luis Suárez con doña Dominga Suárez por derecho a herencia. AHM, Época Independiente, Sección Judicial Civil, Letra S 1812-1860, legajo 2, carpeta 114, folio 16. 
hermano Luis Suárez en los bienes fincados por fallecimiento de Pascual Suárez y Andrea Corvalán padres legítimos de estos litigantes. ${ }^{78}$

Evidentemente, la Carta de Libertad lograda por Dominga había llegado en el momento oportuno. La justicia, con este documento a la vista, puso al mismo nivel a los dos hermanos y resolvió que la herencia debía dividirse en partes iguales.

El sol comenzó a salir para Dominga Suárez con este episodio. Y en los años sucesivos se iban a producir hechos todavía más promisorios para ella y su familia. Sobre todo a través de su hija María Dolores Puebla. Ella había nacido en 1796, siendo registrada como hija natural de Dominga. El padre era "desconocido" pero, probablemente, sería -como de costumbre - un varón de la hacienda Puebla, es decir, un descendiente del capitán Juan de Puebla y Reinoso. La pequeña María Dolores creció y se casó con un pardo esclavo, llamado Juan de la Cruz Torres. De esta unión, nació Gregorio Torres (1819-1879), liberto según acta de bautismo, el cual llevaría adelante los sueños de libertad y creatividad de sus ancestros: en Chile tuvo oportunidad de vincularse al pintor francés Raimundo Augusto Quinsac Monvoisin, el cual realizó una influyente gira por las capitales del Cono Sur de América. Junto a este maestro, Gregorio Torres se nutrió de los conocimientos para convertirse en un artista de primer orden. ${ }^{79}$ Llevó adelante una carrera exitosa hasta llegar a ser el mayor artista plástico regional en los dos primeros tercios del siglo XIX, según la crítica.

Los críticos e historiadores del arte han coincidido en destacar el papel que cupo a Gregorio Torres en la plástica regional. El historiador y crítico de arte de la Universidad de Buenos Aires Jorge Lopez Anaya, en su evaluación de la producción artística argentina, situó a Gregorio Torres entre las principales expresión del arte cuyano del siglo XIX.80 Para Lucio Funes (1937), "Mendoza sólo recuerda a Gregorio Torres como el artista que se destacó antes de (el terremoto de) 1861, que se perfeccionó en Santiago junto al genial francés". ${ }^{11}$ Según la historiadora del Arte, Romera de Zumel, Gregorio Torres fue "el único verdadero valor de nuestra

78 Sentencia del juicio. Mendoza, 4 de noviembre de 1816.

79 Villalobos, Delia. Contribución al estudio de la obra pictórica del siglo XIX en Mendoza. Cuadernos de Historia del Arte, n. 2, Mendoza, 1962, p. 65-66, 70-72.

80 Anaya, Jorge López. Arte argentino, cuatro siglos de historia (1600-2000), (Buenos Aires: EMECE, 2005, p. 82.

81 Funes, Lucio. Recuerdos del Pasado. Mendoza: s/e, 1937, p. 75. 
plástica en aquellos lejanos años". ${ }^{22}$ Por su parte, Morales Guiñazú lo considera "indiscutiblemente el pintor de más aliento que ha tenido Mendoza en sus primeros tiempos". 83

Hasta ahora, la teoría había sostenido que Gregorio Torres pertenecía a las elites socioeconómicas de Cuyo. Así por ejemplo, Blanca Romera de Zumel, tal vez la mayor historiadora del arte que ha dado Cuyo, afirmó que este artista había "nacido de familia honorable". ${ }^{84}$ Es preciso contradecir esta afirmación. Gregorio Torres no surgió en el seno de lo que usualmente se llamaba una "buena familia" ni de "gente decente". Al contrario, su linaje lo entroncaba con "gente vil", con una familia de esclavos africanos.

\section{Los esclavos-amantes}

La historia de los Suárez permite comprender con mayor claridad el funcionamiento de las instituciones durante el Antiguo Régimen Colonial. La sociedad se hallaba fuertemente estamentada. En la cumbre se encontraba una minoría privilegiada, formada por los hacendados, los funcionarios reales, los militares y los clérigos. Ellos controlaban las instituciones clave, como el Cabildo, la Real Audiencia, la justicia civil y eclesiástica. Este sector social, a pesar de ser minoritario, mantenía una gran fuerza debido a su cohesión. Había una notable solidaridad de intereses y de estrategias que unía, a través de un lazo invisible, a los hacendados con los clérigos y jueces. De esta manera se aseguraba la conservación del modelo social.

Mirado desde la perspectiva de los sectores subalternos, este sistema parecía muy difícil de modificar. Cambiar de estado, pasar de la esclavitud a la libertad, de la pobreza a la prosperidad económica, del analfabetismo a la Universidad, parecía una utopía, un mundo inalcanzable. Los intentos de romper las amarras del orden social parecían condenados al fracaso. Esta fue la visión que quedó en la conciencia de Andrea Corvalán: ella vio cómo su marido, Pascual Suárez, libraba una batalla desigual por su hijo Luis. El hombre trabajó para pagar, con su sudor, la libertad de su hijo. Luego se sometió a una desgastante lucha jurídica, para lo cual debió ir y venir hacia Buenos Aires y embargar sus bienes. Durante la tramita-

82 Zumel, Blanca Romera de Zumel. El arte en Mendoza en el siglo XIX: el pintor Gregorio Torres. Cuadernos de Historia del Arte, n. 10, Mendoza, 1971, p. 39.

83 Guiñazu, Fernando Morales. Historia de la Cultura Mendocina. Mendoza: Best Hermanos, 1943, p. 442.

84 Zumel, Blanca Romera de. El arte en Mendoza en el siglo XIX: el pintor Gregorio Torres. Cuadernos de Historia del Arte, n. 10, Mendoza, 1971, p. 40. 
ción del pleito en la Real Audiencia, la burocracia capitular se apropió de esos bienes para cobrarse sus servicios. Mientras tanto, enfermo y cansado, Pascual Suárez estuvo postrado y hasta encarcelado. Y después de un lustro de cumplir con las formas jurídicas, la Real Audiencia rechazó definitivamente su reclamo.

La alianza de hacendados, clérigos y jueces no tenía fisuras. Formaba un bloque pétreo, inabordable. Las sentencias, una tras otra, eran señales claras para los sectores subordinados: no tenía sentido luchar ni rebelarse contra el régimen; éste tenía suficiente fuerza para reproducirse a sí mismo. Andrea Corvalán se había ilusionado con la idea de ver a su hijo libre. Por eso participó de la lucha familiar. Pero luego se quedó con las manos vacías y dejó de vivir. Con su muerte y la confirmación de la esclavitud de su hijo, el régimen se anotaba una muestra de su poder.

Ese era el mensaje que se emitía a los sectores populares de la sociedad colonial. El mejor camino que les quedaba era acatar la realidad existente y someterse a la autoridad de sus amos, respetar a los jueces y temer a los clérigos. No existían opciones válidas.

Después de la Revolución de 1810, iban a soplar nuevos vientos. Se abolió la esclavitud y se reivindicaron ciertos derechos políticos. Pero en muchas regiones, sobre todo en las áreas rurales, el sistema de poder de los hacendados iba a quedar, por un buen tiempo, más o menos intacto. Los sectores subordinados llevaban 300 años de disciplinamiento a través de las instituciones coloniales. ¿Para qué luchar? ¿Por qué intentar cambiar el orden de cosas, si es una tarea casi imposible?

Esta fue una de las victorias del régimen colonial. La otra fue la cultura de falta de solidaridad entre los sectores subordinados. Así lo reflejó Luis Suárez. Su lucha no fue para modificar el sistema, sino para cambiar su posición relativa dentro de éste y aprovecharla en beneficio propio. Luis experimentó los rigores de la esclavitud en su propio pellejo. Pero cuando se liberó de este yugo, procuró imponerlo a sus familiares para lucrar con la vigencia del régimen esclavista. Muy pronto olvidó los actos solidarios de su hermana para ayudarlo a alcanzar su libertad; poco le importó la memoria de sus padres, que trataron de dejarle una herencia de amor. Luis no pudo interpretar estas señales. El sistema no le dejaba espacio para ello. Pero nosotros sí podemos hacerlo ahora, aunque hayan pasado 300 años.

Más allá de los aspectos grises y negros de esta historia, queda un foco de luz que brilla como una antorcha en la oscuridad de la vida colonial. Se trata del amor de Pascual y Andrea por su familia, particularmente por su hijo. Ellos le dieron un sentido a sus vidas con 
la construcción de un sueño, una utopía. Imaginaron un mundo mejor y lucharon por conseguirlo. Trabajaron, sudaron y litigaron por amor a su hijo. Sufrir la pobreza, el desaliento y la tristeza. Desde el amor sacaron las fuerzas para salir adelante y dejar un legado. Este no fue recogido por su hijo Luis, pero sí por Dominga que supo, a su vez, trasmitirlo a los suyos. Y en los pinceles del pintor Gregorio Torres florecería este torbellino de amor con sangre esclava.

La vida de los Suárez representa la de muchos chilenos que también nacieron en un contexto de subordinación, en familias pobres. Muchas de estas historias han quedado ocultas y desconocidas porque no existieron testimonios de ellas. En este caso, el pleito judicial permitió reconstruir esta memoria vital, profunda, cargada de emociones. En este sentido, la historia de Pascual y Andrea es una historia de sufrimiento, pobreza y trabajo. Pero también una historia de dignidad, de espíritu de lucha y sobre todo, de amor. Amante, etimológicamente, es la persona que ama. Andrea y Pascual fueron amantes; esclavos-amantes. Y en este sentido, su historia vale por sí misma.

La revolución de 1810 generó un nuevo contexto de cambio social. Y uno de los planos en donde se iba a sentir el cambio de régimen iba a ser, precisamente, en el final de la esclavitud. En el Cono Sur se comenzó a superar este modelo mediante la libertad de vientres, proclamada en 1811 en Chile y en 1813 en Argentina. A partir de entonces, los hijos nacidos de madre esclava, como Luis Suárez, serían libres. El paso siguiente sería la abolición total de la esclavitud. A mediados de 1821 Chile se convirtió en el primer país del mundo que proclamó la libertad de sus esclavos. ${ }^{85}$ Argentina demoró esta medida debido a las guerras civiles y la influencia de los caudillos conservadores como el dictador Rosas. Pero inmediatamente después de la caída de éste, también se sancionó la abolición de la esclavitud en la Argentina (1853). De esta manera se cerraba el proceso emancipatorio iniciado en la revolución de 1810. En otros países americanos la esclavitud se mantuvo vigente hasta bien entrada la segunda mitad del siglo XIX. EEUU terminó con ella recién después de la guerra de secesión (1865); Brasil fue una colmena de esclavos hasta la caída del imperio y la proclamación de la república (1885); y Cuba terminó con este sistema mediante su tardía guerra de independencia de España (1898).

85 Antes de Chile, Dinamarca también había proclamado la abolición de la esclavitud; pero esa fue una medida sólo teórica, pues en ese país no existían esclavos. 